\title{
Schedule control of eating by fixed-time schedules of water presentation
}

\author{
CORA LEE WETHERINGTON \\ University of North Carolina at Charlotte, Charlotte, North Carolina 28223 \\ and \\ AARON J. BROWNSTEIN \\ University of North Carolina at Greensboro, Greensboro, North Carolina 27412
}

\begin{abstract}
Eating was measured in water-deprived rats when water was presented at regular intervals ranging from 30 to $240 \mathrm{sec}$. The temporal patterning of eating resembled that of scheduleinduced behavior in that the probability of eating was high early in the interval and declined in the end of the interval. Additionally, (a) the number of pellets consumed was controlled by relative time in the interwater interval, (b) the pellets consumed per water presentation was inversely related to water rate, and (c) food-ingestion rate was directly related to water rate. These relationships parallel those found with behavior regarded as schedule induced.
\end{abstract}

Since Falk's (1961) report of schedule-induced polydipsia (SIP) in rats barpressing on a variableinterval (VI) 1-min schedule of food reinforcement, much research has been devoted to extending the generality of schedule-induced phenomena. Specifically, research has addressed generality with respect to four major parameters: the induced behavior, the inducing schedule, the inducing event, and the experimental species.

Research has now established generality with respect to each of these parameters. First, scheduleinduced behavior is not restricted to water consumption. A wide variety of behaviors can be induced by food schedules, for example, attack, escape, pica, alcohol ingestion, and air licking. Second, within a range of interfood intervals, most intermittent food schedules, with or without a response requirement, will generate schedule-induced behavior. Third, schedule-induced behavior has been reported not only in rats, but in pigeons, chickens, monkeys, and mice (see reviews by Falk, 1971; Staddon, 1977). Finally, schedule-induced behavior is produced not only by schedules of food, but also by schedules of water (King, 1974) and running-wheel availability (Singer, Wayner, Stein, Cimino, \& King, 1974).

Despite these generalities, there are several interesting failures to observe schedule-induced behavior.

\footnotetext{
This research was supported in part by funds from the Foundation of the University of North Carolina at Charlotte and from the State of North Carolina. It was presented at the 1977 convention of the Psychonomic Society in Washington, D. C. The technical assistance of Charles Bragg and Carol Johnson is gratefully acknowledged. Reprints may be obtained from Cora Lee Wetherington, Department of Psychology, University of North Carolina at Charlotte, Charlotte, North Carolina 28223.
}

For example, neither pigeons (Carlisle, Shanab, \& Simpson, 1972) nor rats (King, 1974) engage in schedule-induced eating when water is presented intermittently. Further, rats do not engage in scheduleinduced aggression when food is intermittently presented (Hymowitz, 1971; but see Knutson \& Schrader, 1975).

The defining characteristic of SIP which originally generated research interest was the excessiveness of the quantity of water consumed when food was intermittently scheduled. Accordingly, excessiveness is regarded as the appropriate measure for assessing the occurrence of schedule-induced behavior. However, a failure to observe schedule induction, so defined, does not preclude the possibility that the behavior is, nevertheless, under the control of the schedule in terms of temporal patterning. This possibility was addressed in the present experiment in the context of eating during intermittent schedules of water presentation.

\section{METHOD}

\section{Subjects}

Subjects were three male albino Holtzman rats, approximately 6 months old at the start of the experiment. They had been briefly exposed to a variety of schedule conditions during an undergraduate laboratory course.

\section{Apparatus}

Four standard rodent operant conditioning chambers (BRS/ LVE Model 1310) equipped with a pellet dispenser and a water dipper were used. Programming and data recording were accomplished by standard electromechanical devices. Extraneous sounds were masked by white noise.

\section{Procedure}

Preliminary training. The rats were reduced to $80 \%$ of their 
ad-lib weights, and leverpresses for food were shaped. Three daily 1-h sessions of approximately 100 reinforcements each were required to establish a steady response rate. The rats were then allowed to recover their free-feeding weights.

Experiment proper. The rats were placed on a water-deprivation regimen in which water was freely available for $1 \mathrm{~h}$ in the home cage following each experimental session. Thus, the rats were nominally $22 \mathrm{~h}$ deprived at the start of each $1-\mathrm{h}$ experimental session.

The experimental manipulation consisted of exposing the rats to a variety of fixed time (FT) presentations of water $(.04 \mathrm{ml})$ with interwater presentations ranging from 30 to $240 \mathrm{sec}$. The order of experimental conditions and corresponding number of sessions (in parentheses) were as follows: Rat R1-FT 60 (18), FT 60 (18), FT 30 (18), FT 120 (31); Rat R2-FT 60 (18), FT 60 (18), FT 30 (18), FT 120 (31), FT 30 (18), FT 240 (67); Rat R4FT 60 (18), FT 60 (18), FT 30 (18), FT 120 (31), FT 30 (18), FT 240 (33). An experimental condition not relevant to the present experiment intervened between the FT 60 conditions. Throughout all conditions, each leverpress produced a food pellet. Conditions remained in effect until there was little day-to-day variability in the total number of food responses and in the distribution of food responses in the interwater interval. Leverpresses were recorded separately for successive 10ths of the interwater interval.

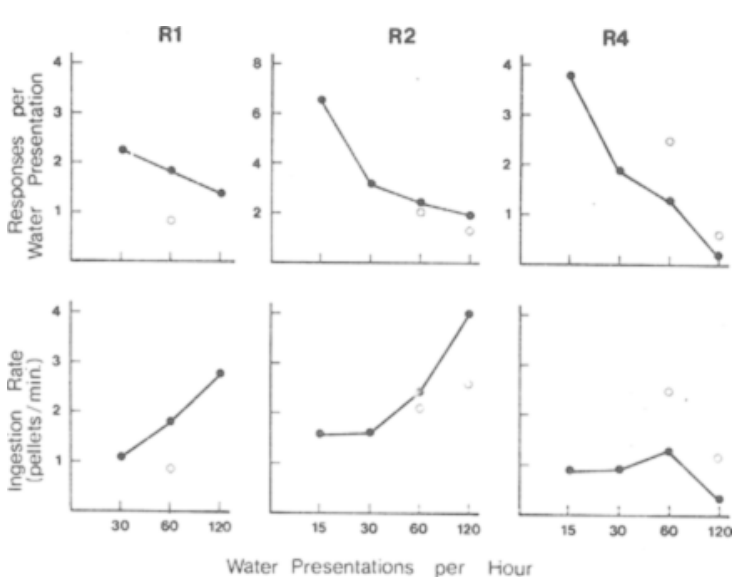

Figure 2. Upper panel: Number of food pellets consumed per water presentation as a function of the rate of water presentation. Lower panel: Rate of food ingestion as a function of the rate of water presentation. Unconnected open circles represent redetermination points.

\section{RESULTS}

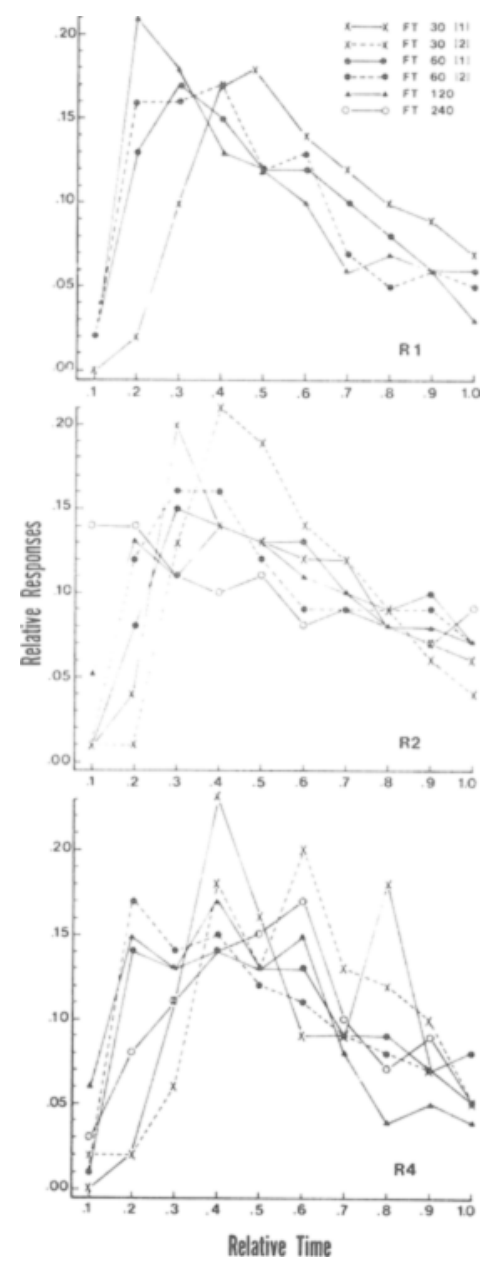

Figure 1. Relative number of food responses as a function of relative time in the interwater interval.
Figure 1 shows, for each rat, the relative number of food responses (i.e., leverpresses) as a function of the relative time in the interwater interval for each of the FT values. The data points of each curve represent the mean of the last 5 days of the condition. For each rat, relatively less eating occurred immediately after and immediately prior to water presentation. There is considerable overlap in the functions for each rat, indicating that the differential tendency to eat within the interwater interval does not simply indicate the absolute time course of eating after drinking. If eating had been under the control of absolute time in the interval, plotting the relative responses as a function of relative time in the FT would have yielded a family of functions whose peaks increased and were successively displaced to the left at longer FT values.

Figure 2 shows two additional measures of eating. The upper panel shows the mean number of leverpresses per water presentation as a function of the rate of water presentation. For each rat, these curves are decreasing. The lower panel shows the rate of food ingestion as a function of the rate of water presentation. Since rats ate pellets as quickly as they produced them, ingestion rates were based on leverpress rates (Skinner, 1938). For Rats R1 and R2, the functions are increasing; for Rat R4, the function was less discernible.

\section{DISCUSSION}

Although previous research (King, 1974) failed to demonstrate the induction of excessive eating by scheduling water, the eating observed in the present 
experiment yielded three correspondences with behavior regarded as schedule induced. First, the control of eating by relative time in the interwater interval parallels a report by Killeen (1975) that the pattern of drinking under the control of food presentations was a function of relative time in the interfood interval.

Second, the number of pellets consumed per water presentation decreased as a function of the rate of water presentation. Although the comparable functions for schedule-induced behaviors such as drinking, attack, and escape are typically reported to be inverted U-shaped, decreasing functions for scheduleinduced drinking have been reported by Cohen (1975). He speculated that the functions would have eventually declined had lower food rates been used. Perhaps this is also the case for the present data.

Third, the rate of pellet ingestion increased as a function of the rate of water presentation for two of the three rats. This relationship parallels that reported for schedule-induced drinking.

The three measures of eating in the present experiment correspond with measures of behavior obtained in many situations where schedule-induced behavior has been reported. Yet, according to the excessiveness criterion, previous research (King, 1974) has shown that scheduling water does not generate schedule-induced eating. There are considerations which might predict that scheduling water should not generate excessive eating. It is reasonable to expect that different behaviors may vary with regard to constraints on how excessive they can be. Obviously, the rat can process excessive quantities of water more easily than excessive quantities of food. In addition to such properties of the induced behavior, the interaction between the deprivation state correlated with the scheduled event and the induced behavior may be another source of constraint on excessiveness. For example, it is well established that water-deprived rats eat less than non-water-deprived rats. Factors such as these may preclude induction of excessive consumption of food by intermittently scheduled water. Such considerations would suggest that the distributional properties of behavior across time (Figure 1), rather than excessiveness, is perhaps a more characteristic outcome of presenting noncontingent reinforcement.

It would be unfortunate if the lawful relationships of the type indicated by the control of eating generated by scheduling water were ignored because eating was not excessive. A more comprehensive label such as schedule-modulated behavior would more likely foster concern for temporal regularities as well as schedule-induced effects.

\section{REFERENCES}

Carlisle, H. J., Shanab, M. E., \& Simpson, C. W. Scheduleinduced behaviors: Effeci of intermittent water reinforcement on food intake and body temperature. Psychonomic Science, 1972, 26, 35-36.

Conen, I. L. The reinforcement value of schedule-induced drinking. Journal of the Experimental Analysis of Behavior, 1975, 23, 37-44.

FALK, J. L. Production of polydipsia in normal rats by an intermittent food schedule. Science, 1961, 133, 195-196.

FALK, J. L. The nature and determinants of adjunctive behavior. Physiology \& Behavior, 1971, 6, 577-588.

Hyмowitz, N. Schedule-induced polydipsia and aggression in rats. Psychonomic Science, 1971, 23, 226-228.

Killeen, P. On the temporal control of behavior. Psychological Review, 1975, 82, 89-115.

KING, G. D. Wheel running in the rat induced by a fixed-time presentation of water. Animal Learning \& Behavior, 1974, 2, 325-328.

Knutson, J. F., \& Schrader, S. P. A concurrent assessment of schedule-induced aggression and schedule-induced polydipsia in the rat. Animal Learning \& Behavior, 1975, 3, 16-20.

Singer, G., W Ayner, M. J., Stein, J., Cimino, K., \& King, K. Adjunctive behavior induced by wheel running. Physiology \& Behavior, 1974. 12, 493-495.

Skinner, B. F. The behavior of organisms. New York: AppletonCentury-Crofts, 1938.

Staddon, J. E. R. Schedule-induced behavior. In W. K. Honig \& J. E. R. Staddon (Eds.), Handbook of operant behavior. Englewood Cliffs: Prentice-Hall, 1977.

(Received for publication February 22, 1978; revision accepted July 20,1978 .) 